\title{
Mystery of the Toxic Flea Dip: An Interactive Approach to Teaching Aerobic Cellular Respiration
}

\author{
A. T. Baines, ${ }^{*}$ M. McVey, B. Rybarczyk, J. T. Thompson, and H. R.Wilkins
}

Department of Biology, University of North Carolina, Chapel Hill, NC 27599-3280

Received for publication June 5, 2003; accepted August 12, 2003.

\begin{abstract}
We designed an interrupted case study to teach aerobic cellular respiration to major and nonmajor biology students. The case is based loosely on a real-life incident of rotenone poisoning. It places students in the role of a coroner who must determine the cause of death of the victim. The case is presented to the students in four parts. Each part is followed by discussion questions that the students answer in small groups prior to a classwide discussion. Successive parts of the case provide additional clues to the mystery and help the students focus on the physiological processes involved in aerobic respiration. Students learn the information required to solve the mystery by reading the course textbook prior to class, listening to short lectures interspersed throughout the case, and discussing the case in small groups. The case ends with small group discussions in which the students are given the names and specific molecular targets of other poisons of aerobic respiration and asked to determine which process (i.e., glycolysis, citric acid cycle, or the electron transport chain) the toxin disrupts.
\end{abstract}

Keywords: undergraduate, electron carrier, electron transport chain, energy, enzyme, glycolysis, Krebs cycle, mitochondria, thermodynamics, adenosine triphosphate

\section{INTRODUCTION}

The topic of aerobic cellular respiration is particularly difficult for undergraduate science students to comprehend. For students to fully comprehend aerobic respiration, they must master difficult concepts including reduction/oxidation reactions, thermodynamics, functions of enzymes, and concentration gradients. Novice learners have a wide range of misconceptions that must be overcome in order to achieve deep understanding (Songer and Mintzes, 1994). For example, students often associate respiration only with breathing as opposed to the conversion of energy by cells. Furthermore, some of these misconceptions persist after intensive instruction, and new ones may arise for experienced biology students (Songer and Mintzes, 1994).

Many students unfamiliar with cellular respiration seem to get lost in the memorization of details rather than focusing on the overall process and purpose of cellular respiration. An additional difficulty for instructors is that introductory biology courses commonly must serve both majors and nonmajors, sometimes in the same classroom. These students have different expectations and motivations for being in the class, thus making judgments about the level of detail to teach difficult for the instructor. Previous experiences teaching aerobic cellular

DOI: $10.1187 /$ cbe.03-06-0022

"Corresponding author: Department of Biology CB\#3280 Coker Hall University of North Carolina Chapel Hill, NC 27599-3280. E-mail address:antonio_baines@med.unc.edu. respiration solely using a lecture format did not result in the student learning outcomes that we and other instructors desired: primarily, successful application of concepts on exam questions (see Haslam and Treagust, 1987). Based on responses to questions in class and performance on exams, students (both majors and nonmajors) not only had difficulty learning the material but also in placing the concepts into a broader biological context.

We devised an interactive way to teach aerobic cellular respiration to increase student comprehension and understanding of biological key concepts about cellular respiration. The activity presented here follows an interrupted case study method. Traditionally, the case study method has been used in the disciplines of law, business, and medicine. Recently, however, it has been used in science education (Herreid, 1994). The case study we present is based on an actual case of rotenone poisoning of a young girl (De Wilde, 1986). Rotenone is a naturally occurring chemical derived from the roots of several tropical and subtropical plants. It inhibits chemiosmosis by interfering with NADH dehydrogenase preventing utilization of $\mathrm{NADH}$ as a proton and electron donor in the electron transport chain (WHO; Extoxnet Pesticide Information Notebook Rotenone, 1996; Rotenone Health and Safety Guide, Number 73).

Using this real world story, the case instantly captivates the students' interest and also provides them with an immediate application of the subject. This case can serve as an alternative to a traditional lecture or laboratory or can supplement existing activities and assignments. We provide the case (in four sections) along with a preliminary assessment and evaluation of 
student outcomes at institutions that used the case in undergraduate introductory biology courses.

\section{TEACHING NOTES}

\section{Objectives of the Lesson}

1. Describe the purpose and process of cellular respiration including reactants, products, and cellular location of reactions

2. Explain how ATP molecules are produced by the electron transport chain

3. Describe why oxygen is important in the process of cellularrespiration

4. Analyze a case study and solve problems based on scientific data

\section{Courses and Student Demographics}

The case study was used in Principles of Biology, an introductory course for both majors and nonmajors at the University of North Carolina at Pembroke (UNC-Pembroke). The course met for one 2.5 -h session each week. The duration of the case study was one full class period. There were $36 \mathrm{stu}$ dents in the class; four were biology majors and 32 were nonmajors. Most of the students were nontraditional; 29 of the students were older than $22 \mathrm{yr}$ and 16 students had children. More than $60 \%$ of the students were Native American, African American, and Hispanic American. The remainder of the students were Caucasian. The majority of students lived in rural North Carolina.

This case study was also used in General Biology, an introductory class for majors and nonmajors at Shaw University. The course met for two, 2.5-hr sessions per week. The duration of the case study was one full class period. There were 54 students; 33 biology majors, and 21 nonmajors in the class. Fortyfour of the students were freshman, and the average age was 19 yr. Most students ( $95 \%)$ were African American. The remainder of the students were Hispanic American and Caucasian. Most students lived in Raleigh, NC.

\section{Preparation for the Case Study}

At UNC-Pembroke, cellular respiration was taught in the context of a unit on the "Life of the Cell." Prior to the case study, the students learned about the major types of macromolecules, the names and basic functions of cell organelles, and the special properties of the plasma membrane. At Shaw University, this case study was taught during the "Energy" unit. Topics covered in prior class sessions included macromolecules, cell organelles, diffusion and osmosis.

Prior to the start of the case study, the students in each class were given a take-home quiz on how a single glucose molecule is converted into ATP by the cell. The quiz was not particularly challenging but required the students to read the textbook. On the quiz, the students were asked to define ATP, ADP, glycolysis, Krebs cycle, the electron transport chain, and electron carriers, describe precisely where in the cell glycolysis, the Krebs cycle, and the electron transport chain occur, and list how many ATP, NADH, and $\mathrm{FADH}_{2}$ are manufactured from a single glucose molecule by glycolysis, the Krebs cycle, and the electron transport chain.

\section{Teaching Methods}

We presented information to the students as an interrupted case study. The students worked in groups of three to four per group through each part of the case.

In Part 1, we introduced the case study as a mystery that the students would solve. We asked the student groups to read Part 1 of the case and to discuss the answers to the questions. The questions, which were intentionally open-ended, generated enthusiastic and animated discussion. Students brainstormed ways the girl may have been poisoned by the flea dip. Many of them pointed out the increased susceptibility of children to toxins and the likelihood that she drank or aspirated some of it. Some students even recognized the ethical issues of allowing the child to use the flea dip unattended. Many of the students suspected that rotenone was the cause of her death. Five minutes into the discussion, we told the class that rotenone was the poison responsible for the death of the girl. We also provided a brief background about sources of rotenone and its use by humans. This information stimulated an additional $10 \mathrm{~min}$ of discussion. The students raised several excellent points, including: Why don't farmers who apply rotenone pesticides get sick? Why does it kill insects but not humans or pets? What purpose does it serve in the plants that produce it? Is rotenone now banned from flea dip?

Next, we presented Part 2 of the case study and asked the student groups to answer the question. We wanted the students to determine that the poison affected energy processing in the mitochondria. This question forced the students to recall previous material on the general categories of organelle function. Most groups had to refer back to their notes or the textbook before answering. All students eventually came to the conclusion that they needed to focus on mitochondria and cellular respiration.

After Part 2, we interrupted the case to present a twenty minute lecture on energy. The students were told they needed more information to determine exactly how the poison killed the girl. At UNC-Pembroke, the lecture included the first and second laws of thermodynamics, diffusion and active transport, and an introduction to enzymes. At Shaw University, the instructor explained the major steps of cellular respiration including the location of reactions, the reactants, products and the number of ATP molecules produced at each step. The lecture covered energy, concentration gradients, and enzymes. Multiple illustrations were included in the presentation for visual learners.

Following the lecture, we presented Part 3 of the case study. Students were asked to discuss what step rotenone affected. Working in small groups, the students successfully narrowed down the possibilities to the Krebs Cycle or the Electron Transport Chain. They were able to recognize what steps of aerobic cellular respiration occur within the mitochondria.

The case study was interrupted for a second lecture after the student groups presented their answers to the discussion question in Part 3. The duration of the lecture was 30 minutes and included an overview of the Krebs cycle and chemiosmosis. It covered redox reactions, electron carriers and the transfer of energy by electrons, a review of electronegativity and the importance of oxygen, active transport, and diffusion in chemiosmosis. This lecture built upon the basic material the students had encountered on the take-home quiz.

After the lecture, we presented Part 4 of the case study and asked the student groups to answer the discussion questions. 


\section{The Case:}

You're working at the medical examiner's office at San Francisco County Hospital. It has been a particularly light day, with only 1 homicide and a dead chipmunk that you checked over for rabies. The chipmunk didn't have rabies, and you're ready to go home. Just as you're flipping the switch, you get a call from your secretary. "Francesca," he says. "We've got a dead kid up here that you'll want to look at right away. Might be foul play."

Thinking of your four-year old daughter waiting for you at home, you grimace. "OK Jon, l'm heading to the morgue." Performing autopsies on kids is the least favorite part of your job. But you are paid to solve medical mysteries, and it looks like you've got one here.

In the morgue, you find the report from the hospital. Glancing over it, you notice a narrative of the girl's last hours and read it carefully:

At $10 \mathrm{AM}$, mother returns from the store to find girl vomiting, not feeling well, and sleepy. Mother put girl to bed. Ten minutes later, she noticed that the child's breathing became irregular and slow. She tried to wake her daughter but was not able to do so. The child became comatose. At noon, the girl was admitted to the hospital, with no heartbeat or spontaneous breathing.

A police report states the following:

The parents discovered that the girl had been giving her dog a bath using a flea dip called Fleacide. According to the label on the container, Fleacide is an insecticide made of plant material only and appropriate for external use on animals.

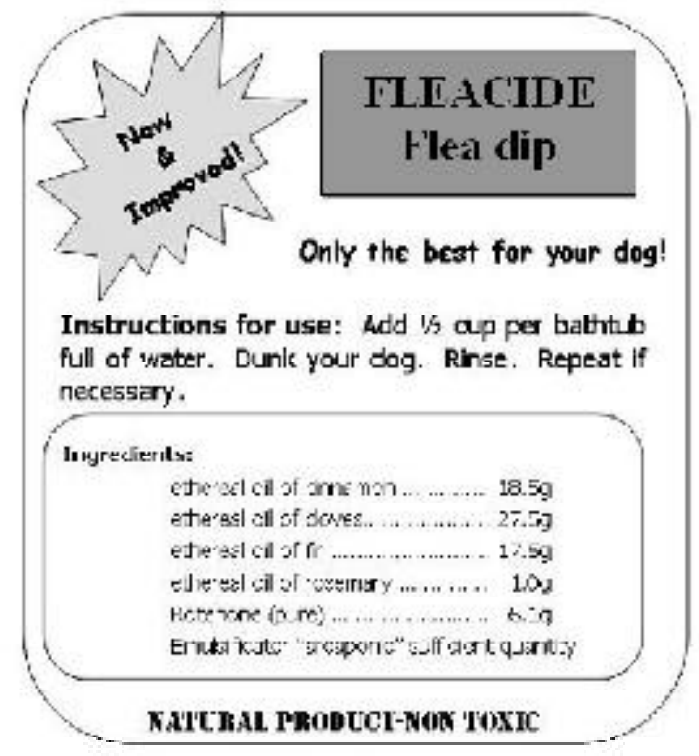

Part 1: The Flea Dip

\section{Questions:}

1) What could have been in the flea dip that killed the girl?

2) How could a product that is normally harmless to humans and pets have killed the girl?

\section{Part 2: Autopsy Report}

- The girl died within two hours of first vomiting

- Immediate cause of death was hypoxia (lack of oxy gen)

- Tissue sections from the kidneys, lungs, thymus, and heart show massive cell death

- Staining with cellular dyes indicates that the mitochondria within the affected tissues were damaged

\section{Question:}

1) Given the autopsy report, and recalling your knowledge from your reading about the functions of cellular organelles, what functions of the cell did the Fleacide affect?

\section{Part 3: ATP Analysis}

A more detailed analysis of the cells from the girl's heart showed that ATP levels were reduced in the mitochondria. ATP levels in the cytoplasm of these cells, however, were normal. In addition, acetyl-CoenzymeA levels were normal.

\section{Question:}

1) What cellular process (or processes) was impaired by the Fleacide?

\section{Part 4: Subcellular Analysis}

Using a new chromatographic technology developed late last year, you are able to determine the levels of various subcellular components in the heart cells. Key highlights of the report are listed below:

\begin{tabular}{|c|c|c|}
\hline Metabolite & Autopsy Finding & Normal Levels \\
\hline$\overline{\text { Glucose }}$ & $\overline{102 \mu \mathrm{mol}}$ & $100 \mu \mathrm{mol}$ \\
\hline Pyruvate & $23 \mu \mathrm{mol}$ & $25 \mu \mathrm{mol}$ \\
\hline NAD+ & $6 \mu \mathrm{mol}$ & $75 \mu \mathrm{mol}$ \\
\hline $\mathrm{NADH}$ & $383 \mu \mathrm{mol}$ & $50 \mu \mathrm{mol}$ \\
\hline
\end{tabular}

\section{Questions:}

1) Given this new information, what specific cellular process do you think was affected by the Fleacide? Why?

2) Some health food stores sell supplements containing $\mathrm{NAD}+$. If you administered the supplement to the girl, could you save her? Why or why not?

3) Would artificial respiration or oxygenation save the girl? Why or why not? 
The students immediately recognized that the concentrations of $\mathrm{NAD}^{+}$and NADH from the autopsy were very different from normal levels. Although this part of the case study was difficult for many students, several understood that part of the electron transport chain was inhibited by the rotenone. These students explained the information to other group members with very little input from the instructor. The students raised in-depth discussion questions, and ultimately agreed upon the action of rotenone. The second question generated the most discussion. At first, many students thought that the imbalance between $\mathrm{NAD}^{+}$and NADH was the primary problem. However, some students soon determined that the imbalance was merely a result of the action of rotenone. These students convinced the others of their view without input from the instructor.

Finally, as a homework activity students at UNC-Pembroke were given the names and characteristics of other poisons that interfere with cellular respiration (e.g., arsenate and cyanide) and asked to determine what other energy processes they might affect (see Illingworth, 2001).

\section{EVALUATION}

\section{Effectiveness of the Case Study}

Our goal was to assess the effectiveness of using the case study to increase student comprehension and retention of cellular respiration concepts. We assessed student comprehension quali- tatively by monitoring the discussions in the student groups and through the level and sophistication of questions the students asked during class. Semiquantitative assessments were made through a written exam and student satisfaction was assessed with a brief survey after the implementation of the case study.

Since the case was discussed during class in student groups, student-to-student teaching occurred as noted by the instructors. Usually, a student in the group would suggest an answer to his or her respective group and explain the reasoning and supporting evidence for the proposed answer. In response, some students proposed alternative answers to the case questions within the groups. Instructors monitored verbal responses within groups and mediated further discussion by asking questions to the groups that seemed to be off target. Although not all of the students were able to answer the case study questions initially, most students were able to provide correct answers after group discussions.

In one instructor's class, students performed better when taught using the case study relative to a previous semester in which cellular respiration was taught solely by the lecture method. The level and sophistication of the discussions and students' questions was much higher when the case study was used. In addition, when given very similar exam questions, $70 \%$ of the case study students answered correctly compared to only $50 \%$ of the students who were taught by lecture only.

During the class period following the case study, the students were given an oral and written quiz. The questions reviewed

\section{Figure 1: Example of exam question to assess student learning}

Halry was very thirsty, he accidentally crank a poisor named DCCD, lo que 10 i his It irst. Novi $t$ e is feeling ext rausled end tirod. He docides to lie down. Since you've stud ed collular osp ration in your bislogy class tarry is hoping that you are able to determine where the problen is

The facts:

- $\mathrm{O}_{2}$ is presert

- Harry is u ily producing 4 ATP mulecules pe gucuse molecule

Pyruvate is resen: in the cytcecl and acctyl $\mathrm{Co} \Lambda$ is present in the ni:ochondria

- NARH is at ormal levels

a) Label the diagram selo $N$ with the 4 seps of cellullar respira:ion in the correct order. ndicate the number of ATP nolecules produced at eash slep:

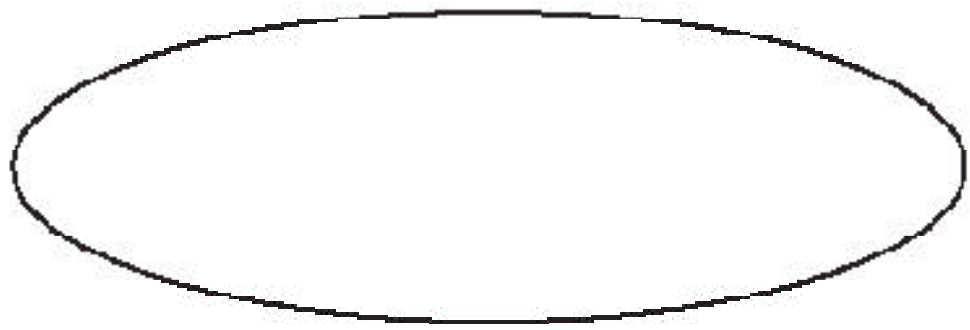

cytoscl

mitcchondria

b) Given the fac:3 above about I lary, where in the celluler respiration pathviay coes DCCD block? Ilo' do you know? (support your answer w th evicence). 
the steps of cellular respiration in detail. As a class exercise, the students were able to explain orally the steps of cellular respiration including the location of where each reaction occurs, the reactants and products, and the purpose of oxygen in this process. A similar case study question was presented to the students on a mid-term exam (Figure 1). This question asked about a different poison that blocked aerobic cellular respiration in the mitochondria. The students were asked to make a diagram of cellular respiration including the cellular location and number of ATP molecules produced during each step. The students were given data similar to the toxic flea dip case study from which they determined where the block in cellular respiration occurred. About $80 \%$ of the students responded with correct answers to this question. Another measure of assessment was a concept map as a final semester project. The class that did not use the case study was not given a concept map assignment. Of the students who used the case study, approximately $80 \%$ successfully integrated cellular respiration into their concept map, suggesting that they comprehended important concepts about cellular respiration.

\section{Student Satisfaction}

Using a feedback survey, we set out to probe student perceptions and to determine if the students felt that the case study increased their understanding of cellular respiration. In general, the students responded positively to the case study as a learning tool. After completing the case study, $75 \%$ of the students ( 21 of 28 students polled) felt that they understood the steps of cellular respiration and that the case study helped them learn concepts more effectively than a traditional lecture (Figure 2). When asked what the most useful part of the activity was for them, students most frequently responded with: the discussion, the questions, and the ability to use the information in a real-life situation (Figure 2).

\section{Addressing Student Misconceptions}

Previous studies have shown that misconceptions about cellular respiration can persist in the minds of students, even after they have been exposed to varied instructional methods (Haslam and Treagust, 1987; Songer and Mintzes, 1994). We observed that prior to instruction, the vast majority of students associated the word respiration solely with breathing. In addition, they were unable to accurately describe how animals utilize energy stored in food, or how oxygen is used in this process. After instruction using the case study, most students were able to accurately identify cellular respiration as the conversion of food energy into ATP. Furthermore, their responses on exam questions and in their concept maps suggested that they could explain why oxygen was required for the process.

\section{CONCLUSIONS}

We believe that this interrupted case study provides an effective teaching approach that promotes meaningful and connected comprehension of the important concepts related to cellular respiration. The activities are designed to provide students with multiple opportunities to analyze data and apply it to a real-world setting. Throughout the exercise, students must employ critical thinking to make plausible models and then incorporate new data into these models. The use of this case study allows students to work in a collaborative environment, does not require extensive or expensive equipment, can be used in large or small class settings, and can be used to teach both biology majors and nonmajors. The fact that instructors have used this case study with a diverse and nontraditional student population implies that it is transferable to many settings. In conclusion, this case study grounds the principles of cellular respiration to in a true-to-life scenario and enhances critical thinking skills that are applicable to any scientific discipline. This case study provides a low risk, first step for instructors who want to incorporate more active learning strategies into their classroom. More formal and quantitative studies are currently being undertaken to validate the findings of this study and to evaluate the use of case studies as active learning tools to increase improve student learning outcomes.

\section{ACKNOWLEDGEMENTS}

The case study was designed and tested while each author was a fellow in the Seeding Postdoctoral Innovators in Research and Education (SPIRE) program. Formulation and teaching of the case study was supported by the Minority Opportunities in Research Division of National Institute of General Medical Sciences grant GM000678. We thank L. Lerea for comments and suggestions on the manuscript, and W.E. Bollenbacher and the SPIRE fellows for useful discussion during the development of the case study.

\section{Figure 2: Student responses to evaluation survey}

1) After completng the case study, do you fee that you understand the four steps of cellular respiration?

$$
75 \% \text { Yes } \quad 25 \% \text { No }
$$

2) Did you find that using this case study helped you understand the concepts better than just a traditional lecture?

$$
75 \% \text { Yes } \quad 25 \% \text { No }
$$

3) What was most useful part of tris activity?

\section{the class dissussion, the questions, and the ability to use the information in a real-life situation.}




\section{Cellular Respiration Case Study}

\section{REFERENCES}

De Wilde, A.R., Heyndrickx, A., and Carton, D. (1986). A case of fatal rotenone poisoning in a child. J. Foren. Sci. 31, 1492-1498.

Haslam, F., and Treagust, D. (1987). Diagnosing secondary students' misconceptions of photosynthesis and respiration in plants using a two-tier multiple choice instrument. J. Biol. Edu. 21, 203-211.

Herreid, C.F. (1994) Case studies in science-a novel method of science education. J. Coll. Sci. Teaching 23(4), 221-229.

Illingworth, J.A. 2001. http://www.bmb.leeds.ac.uk/llingworth/oxphos/ poisons.htm.
Songer, C.J., and Mintzes, J.J. (1994). Understanding cellular respiration: an analysis of conceptual change in college biology. J. Res. Sci. Teaching $31,621-637$.

World Health Organization (1992). Rotenone health and safety guide. Geneva: World Health Organization.

Extoxnet Pesticide Information Notebook Rotenone, revised 696.

International Programme on Chemical Society (IPCS), Rotenone Health and Safety Guide, Number 73. 


\section{ANSWERS TO THE DISCUSSION QUESTIONS}

\section{Part 1 Questions:}

1. What could have been in the flea-dip that killed the girl?

The rotenone killed the girl. We did not expect the students to know that rotenone is toxic, only that there was a poison in the flea-dip.

2. How could a product that is normally harmless to humans and pets have killed the girl?

The girl must have had an unusual exposure to or received an abnormally high dose of the flea-dip. She may have swallowed a large quantity of it or aspirated the flea-dip into her lungs. If she aspirated the flea-dip, the extensive vascularization of the lungs would ensure rapid dispersal of the poison throughout her body.

In addition, the youthfulness of the victim may have contributed to her death. Many pharmaceutical products are tested for safety only in adults. A safe level of exposure to the flea-dip for an adult may not be safe for a child.

\section{Part 2 Question:}

1. Given the autopsy report and recalling your knowledge from medical school of the functions of the cellular organelles, what general functions of the cell did the Fleacide probably affect?

The massive cell death in the kidneys, lungs, thymus, and heart indicate that damage occurred at the cellular level. More specifically, the damage to the mitochondria suggests that aerobic respiration was disrupted.

\section{Part 3 Question:}

1. What cellular process (or processes) was impaired by the Fleacide?

The normal levels of acetyl coenzyme $A$ indicate that glycolysis is functioning normally. The absence of ATP from the mitochondria suggests that either the Krebs acid cycle or the electron transport chain were impaired.

\section{Part 4 Questions:}

1. Given this new information, what specific cellular process do you think was affected by the Fleacide? The low levels of NAD+ and the high levels of NADH indicate that the first step in the electron transport chain was disrupted. Specifically, the function of NADH dehydrogenase (which converts the electron carrier, NADH, to NAD+) was blocked by the Fleacide.

2) A product sold in health food stores called Inada contains NAD, what if you administered this to the girl. Could you save her? Why or why not?

Probably not. The low level of NAD+ in the heart cells is merely a symptom of the poisoning. The real problem is that rotenone prevents the transfer of electrons from NADH to the electron transport chain by inactivating NADH dehydrogenase. Thus, adding NAD+ to the cells may ultimately help increase the pool of NADH, but it will not restore the function of the electron transport chain.

3) Would artificial respiration or oxygenation save the girl? Why or why not?

Probably not. The real problem is that rotenone prevents the transfer of electrons from NADH to the electron transport chain by inactivating NADH dehydrogenase. A greater concentration of oxygen does not solve the defect in the electron transport chain. This question addresses the misconception that students may have between respiration and cellular respiration. 